\title{
COMMENTARY
}

\section{Immune status in sepsis: the bug, the site of infection and the severity can make the difference}

\author{
Jean-Marc Cavaillon* and Minou Adib-Conquy \\ See related research by Gogos et al., http://ccforum.com/content/14/3/R96
}

\begin{abstract}
Studying a large number of patients with sepsis, the Hellenic sepsis study group led by Evangello Giamarellos-Bourboulis emphasizes that the nature of the bacterial infection, its origin (community or nosocomial), its site, and its severity exert different pressures on the immune system. Their study illustrates the heterogeneity of patients with sepsis and points out that numerous key parameters of severe infection influence immune status.
\end{abstract}

In a study published in this issue of Critical Care, Gogos and colleagues [1] investigated the influence of the type of bacterial infection, the compartment where it occurs, its origin (community or nosocomial), and its severity (sepsis versus severe sepsis or septic shock) on lymphopenia, on the respective number of mononuclear cell subsets, on apoptosis of circulating mononuclear cells, and on HLA-DR expression on monocytes. The same group had already reported that tumor necrosis factor (TNF) and interleukin (IL)-6 production by lipopolysaccharide (LPS)-stimulated monocytes was lower in sepsis patients with ventilator-associated pneumonia than in patients with sepsis due to other types of infections [2]. These analyses permit clinicians to monitor sepsis patients' immune status, which undergoes numerous modifications gathered under the term 'compensatory anti-inflammatory response syndrome' [3].

Lymphopenia is a hallmark of sepsis. It affects most lymphocyte subsets, although some divergent observations for B lymphocytes exist [4-6]. Importantly, lymphopenia is accompanied by modifications of the $\mathrm{CD}^{+} / \mathrm{CD}^{+}$ ratio and the relative percentage of cellular subsets. For example, among lymphocytes, the percentages of Treg

*Correspondence: jean-marc.cavaillon@pasteur.fr

Institut Pasteur, Unité Cytokines \& Inflammation, Département Infection et Epidémiologie, 28 rue Dr. Roux F-75015 - Paris - France (regulatory T) [7] and of natural killer (NK) [8] cells are enhanced. Lymphopenia already has been associated with bacteremia [9], has been found to be more severe in patients with Gram-positive infection than in those with Gram-negative infection [4], and has been found to inversely correlate with outcome [10]. It can be mimicked by injections of live bacteria, LPS, IL-1, or TNF in animal models. The mechanisms that lead to lymphopenia are mainly a redistribution of activated cells that leave the blood compartment to migrate toward the tissues, particularly toward lymphatic tissues, and the occurrence of apoptosis. Apoptosis of lymphocytes during human sepsis was revealed by the Hotchkiss group [11] when studying the spleens of patients who died of sepsis. Le Tulzo and colleagues [12] showed that apoptosis of circulating lymphocytes was significantly lower in patients with sepsis than in those with septic shock. Hotchkiss and colleagues [13] showed that apoptosis was affecting circulating NK cells, B lymphocytes, and CD4 ${ }^{+}$ and $\mathrm{CD}^{+} \mathrm{T}$ lymphocytes. The reduced HLA-DR expression on $\mathrm{CD}_{14}{ }^{+}$monocytes is another hallmark of sepsis and systemic inflammatory response syndrome. It is a useful prognosis marker of intensive care patients and correlates with the occurrence of sepsis [14]. Measurements performed a few days after the onset of sepsis appear as a prognosis marker, and low expression correlates with poor outcome [15]. IL-10 and glucocorticoids are the main mediators that lower HLA-DR expression, although they act differently on $\mathrm{CD} 14^{\mathrm{HIGH} C D} 16^{\mathrm{NEG}}$ and CD $14^{\text {LOW }}$ CD $16^{\text {POS }}$ monocyte subsets [16].

The present study illustrates the importance of being careful when comparing different reports, which often include different types of patients with sepsis. The heterogeneity of the patients gathered under the term 'sepsis' is a nightmare for anyone who wishes to submit grant applications or articles, since reviewers can easily argue that the studied group is ill defined and too heterogeneous! This study further emphasizes the difficulty of reaching definite conclusions on patients with sepsis when considered as a global group. The conclusions drawn for sepsis patients with pyelonephritis may not be true for sepsis patients with community-acquired 
pneumonia or intra-abdominal infection. However, although the authors report differences, these differences were minimal. Only community-acquired pneumonia was associated with a higher number of NK cells as compared with the other groups, and only intraabdominal infection was associated with an enhanced number of $\mathrm{CD}^{+}$cells. The latter group was the only one with a significantly enhanced number of apoptotic $\mathrm{CD} 8^{+}$ cells. Reduced expression of HLA-DR on CD14 ${ }^{+}$cells was seen mainly in patients infected with Klebsiella pneumoniae or Acinetobacter baumanii. Surprisingly, when patients with sepsis were compared with those with severe sepsis and septic shock, the number of significant differences in terms of the number of circulating NK cells, CD4 ${ }^{+} \mathrm{T}$ lymphocytes, $\mathrm{CD} 8^{+} \mathrm{T}$ lymphocytes, and $\mathrm{B}$ lymphocytes was limited to community-acquired pneumonia and intra-abdominal infection. Such a difference was not seen in patients with nosocomial pneumonia, pyelonephritis, or bacteremia. Enhanced apoptosis of NK and NKT cells was seen mainly in severe sepsis or septic shock caused by nosocomial pneumonia. Finally, HLADR expression was particularly reduced in patients with severe sepsis or septic shock due to pyelonephritis or intra-abdominal infection. Altogether, it is heartening to note that there were fewer differences than similarities between the different sepsis subgroups. Who else but Hippocrates can offer us a conclusion for this study from Greece: 'It is more important to know what sort of person has a disease than to know what sort of disease a person has'.

Abbreviations

IL, interleukin; LPS, lipopolysaccharide; NK, natural killer; TNF, tumor necrosis factor.

\section{Competing interests}

The authors declare that they have no competing interests.

\section{Published: 18 June 2010}

\section{References}

1. Gogos C, Kotsaki A, Pelekanou A, Giannikopoulos G, Vaki I, Maravitsa P, Adamis S, Alexiou Z, Andrianopoulos G, Antonopoulou A, Athanassia S, Baziaka F, Charalambous A, Christodoulou S, Dimopoulou I, Floros I, Giannitsioti E, Gkanas P, loakeimidou A, Kanellakopoulou K, Karabela N, Karagianni V, Katsarolis I, Kontopithari G, Kopterides P, Koutelidakis I, Koutoukas P, Kranidioti H, Lignos M, Louis K, et al:: Early alterations of the innate and adaptive immune statuses in sepsis according to the type of underlying infection. Crit Care 2010, 14:R96.

2. Pelekanou A, Tsangaris I, Kotsaki A, Karagianni V, Giamarellou H, Armaganidis A, Giamarellos-Bourboulis EJ: Decrease of CD4-lymphocytes and apoptosis of CD14-monocytes are characteristic alterations in sepsis caused by ventilator-associated pneumonia: results from an observational study. Crit Care 2009, 13:R172

3. Adib-Conquy M, Cavaillon JM: Compensatory anti-inflammatory response syndrome. Thromb Haemost 2009, 101:36-47.

4. Holub M, Kluckova Z, Helcl M, Prihodov J, Rokyta R, Beran O: Lymphocyte subset numbers depend on the bacterial origin of sepsis. Clin Microbiol Infect 2003, 9:202-211.

5. Roth G, Moser B, Krenn C, Brunner M, Haisjackl M, Almer G, Gerlitz S, Wolner E, Boltz-Nitulescu G, Ankersmit HJ: Susceptibility to programmed cell death in T-lymphocytes from septic patients: a mechanism for lymphopenia and Th2 predominance. Biochem Biophys Res Commun 2003, 308:840-846.

6. Venet F, Davin F, Guignant C, Larue A, Cazalis MA, Darbon R, Allombert C, Mougin B, Malcus C, Poitevin-Later F, Lepape A, Monneret G: Early assessment of leukocyte alterations at diagnosis of septic shock. Shock 2010, Mar 9. [Epub ahead of print].

7. Monneret G, Debard AL, Venet F, Bohe J, Hequet O, Bienvenu J, Lepape A: Marked elevation of human circulating CD4+CD25+ regulatory T cells in sepsis-induced immunoparalysis. Crit Care Med 2003, 31:2068-2071.

8. Giamarellos-Bourboulis EJ, Tsaganos T, Spyridaki E, Mouktaroudi M, Plachouras D, Vaki I, Karagianni V, Antonopoulou A, Veloni V, Giamarellou H: Early changes of CD4-positive lymphocytes and NK cells in patients with severe Gram-negative sepsis. Crit Care 2006, 10:R166.

9. Wyllie DH, Bowler IC, Peto TE: Relation between lymphopenia and bacteraemia in UK adults with medical emergencies. J Clin Pathol 2004, 57:950-955

10. Tschaikowsky K, Hedwig-Geissing M, Schiele A, Bremer F, Schywalsky M, Schuttler J: Coincidence of pro- and anti-inflammatory responses in the early phase of severe sepsis: longitudinal study of mononuclear histocompatibility leukocyte antigen-DR expression, procalcitonin, C-reactive protein, and changes in T-cell subsets in septic and postoperative patients. Crit Care Med 2002, 30:1015-1023.

11. Hotchkiss RS, Tinsley KW, Swanson PE, Schmieg RE Jr., Hui JJ, Chang KC, Osborne DF, Freeman BD, Cobb JP, Buchman TG, Karl IE: Sepsis-induced apoptosis causes progressive profound depletion of B and CD4+ T lymphocytes in humans. J Immuno/ 2001, 166:6952-6963.

12. Le Tulzo Y, Pangault C, Gacouin A, Guilloux V, Tribut O, Amiot L, Tattevin P, Thomas R, Fauchet R, Drenou B: Early circulating lymphocyte apoptosis in human septic shock is associated with poor outcome. Shock 2002, 18:487-494.

13. Hotchkiss RS, Osmon SB, Chang KC, Wagner TH, Coopersmith CM, Karl IE: Accelerated lymphocyte death in sepsis occurs by both the death receptor and mitochondrial pathways. J Immuno/ 2005, 174:5110-5118.

14. Hershman MJ, Cheadle WG, Wellhausen SR, Davidon P, Polk HC: Monocyte HLA-DR antigen expression characterizes clinical outcome in the trauma patients. Br J Surg 1990, 77:204-207.

15. Monneret G, Lepape A, Voirin N, Bohe J, Venet F, Debard AL, Thizy H, Bienvenu J, Gueyffier F, Vanhems P: Persisting low monocyte human leukocyte antigen-DR expression predicts mortality in septic shock. Intensive Care Med 2006, 32:1175-1183.

16. Kim OY, Monsel A, Bertrand M, Coriat P, Cavaillon JM, Adib-Conquy M: Differential down-regulation of HLA-DR on monocyte subpopulations during systemic inflammation. Crit Care 2010, 14:R61.

doi:10.1186/cc9046

Cite this article as: Cavaillon J-M, Adib-Conquy M: Immune status in sepsis: the bug, the site of infection and the severity can make the difference. Critical Care 2010, 14:167. 